\title{
ANÁLISE TÉCNICA E ECONÔMICA PARA IMPLANTAÇÃO DE UM CENTRO DE COLETA SELETIVA EM MONSENHOR PAULO - MG
}

\author{
Leonardo Martins da Silva Arantes \\ Engenheiro Ambiental e Sanitarista pela Universidade Vale do Rio Verde (UNINCOR), Três Corações, \\ MG, Brasil \\ leoarantes_18@hotmail.com \\ Thales Fernandes Leal \\ Engenheiro Ambiental e Sanitarista pela Universidade Vale do Rio Verde (UNINCOR), Três Corações, \\ MG, Brasil \\ thalesfleal@hotmail.com \\ Rosângela Francisca de Paula Vitor Marques \\ Doutora em Recursos Hídricos, professora da Universidade Vale do Rio Verde (UNINCOR), Três \\ Corações, MG, Brasil \\ roeflorestal@hotmail.com

\begin{abstract}
Alisson Souza de Oliveira
Doutor em Recursos Hídricos, professor da Universidade Vale do Rio Verde (UNINCOR), Três

Corações, MG, Brasil

alissonso@hotmail.com
\end{abstract}

\begin{abstract}
RESUMO
Um dos grandes problemas na atualidade está ligado aos resíduos sólidos urbanos, gerados diariamente em quantidades e variedades, causando diversos danos ao meio ambiente. Uma maneira de mitigar esse problema é através do gerenciamento dos resíduos, uma ferramenta muito importante nesse contexto é a coleta seletiva. Nesse contexto, objetivou-se analisar a viabilidade técnica e econômica de implantação de um centro de coleta seletiva no município de Monsenhor Paulo, Sul de Minas Gerais. Foram realizados levantamentos, como a quantificação da geração de resíduos sólidos, análise de custos, estruturas necessárias, ponto de instalação e modo de funcionamento, além de visitas técnicas visando avaliar a coleta seletiva em duas cidades com modelos diferentes, e posteriormente definir uma metodologia de trabalho que melhor se enquadrasse com a realidade local do município. Na estimativa do fluxo de caixa, o custo operacional encontrava-se abaixo do lucro, ou seja, teoricamente o projeto se manteve, porém foi projetado um valor em cima de $100 \%$ da coleta de materiais recicláveis dentro do município, o que seria algo muito distante de acontecer, levando em consideração a cultura tanto local como do País, ou seja, o brasileiro de modo geral não tem o hábito de separar o seu resíduo domiciliar, sendo necessárias ações voltadas para a educação ambiental. Assim, conclui-se que diante dos valores apresentados, e de todas as variáveis de um projeto desse porte poderá acontecer com o apoio e vontade das políticas públicas ou ONG's, sem visar lucros. O grande benefício está na questão ambiental e social.
\end{abstract}

Palavras-chave: Reciclagem. Destinação Final. Sustentabilidade. 


\title{
TECHNICAL AND ECONOMIC ANALYSIS FOR THE IMPLEMENTATION OF A SELECTIVE COLLECTION CENTER IN MONSENHOR PAULO - MG
}

\begin{abstract}
One of the major problems today is linked to urban solid waste, generated daily in quantities and varieties, causing various damages to the environment. One way to mitigate this problem is through waste management, a very important tool in this context is selective collection. In this context, the objective was to analyze the technical and economic feasibility of implementing a Selective Collection Center in the Municipality of Monsenhor Paulo, South of Minas Gerais. Surveys were carried out, such as the quantification of solid waste generation, cost analysis, necessary structures, point of installation and mode of operation, in addition to technical visits aimed at evaluating selective collection in two cities with different models, and subsequently defining a methodology for work that best fit the local reality of the municipality. In the cash flow estimate, the operating cost was below profit, that is, theoretically the project was maintained, but a value above $100 \%$ of the collection of recyclable materials was projected within the municipality, which would be something very far from happening, taking into account both local and country culture, that is, Brazilians in general are not in the habit of separating their household waste, requiring actions aimed at environmental education. Thus, it is concluded that given the values presented, and all the variables, that a project of this size, can happen with the support and willingness of public policies or NGOs, without aiming at profits. The big benefit is in the environmental and social issue.
\end{abstract}

Keywords: Recycling. Final Destination. Sustainability.

Recebido em: 07/10/2020. Aceito em: 27/01/2021. 
ANÁLISE TÉCNICA E ECONÔMICA

PARA IMPLANTAÇÃO DE UM

CENTRO DE COLETA SELETIVA EM

MONSENHOR PAULO - MG
Leonardo Martins da Silva Arantes

Thales Fernandes Leal

Rosângela Francisca de Paula Vitor Marques

Alisson Souza de Oliveira

\section{INTRODUÇÃO}

O desenvolvimento econômico, o crescimento populacional, a urbanização e a revolução tecnológica vêm sendo acompanhados por alterações no estilo de vida e nos modos de produção e consumo da população. Em decorrência direta desses processos, vem ocorrendo um aumento na produção de resíduos sólidos, tanto em quantidade como em diversidade. Além do acréscimo na quantidade, os resíduos produzidos atualmente passaram a abrigar em sua composição diversos elementos perigosos aos ecossistemas e à saúde humana.

De acordo com o IPEA (2012), a composição gravimétrica dos Resíduos Sólidos Urbanos (RSU) é de $51,4 \%$ de matéria orgânica, $31,9 \%$ de recicláveis e 16,7\% de rejeito. A ABRELPE (2016) tem em suas projeções de geração de resíduos, sendo que os números referentes à geração de RSU revelam um total anual de quase 78,3 milhões de toneladas no Brasil, o montante coletado em 2016 foi de 71,3 milhões de toneladas, uma cobertura de coleta de $91 \%$ para o país, consequentemente $9 \%$ tiveram destino impróprio.

Esses resíduos, acondicionados em aterros, descartados de maneira ambientalmente inadequada, podem comprometer a qualidade do solo, da água e do ar, por serem fontes de materiais poluentes (LANZA, 2009).

Segundo Gouveia e Prado (2010), com a decomposição de matéria orgânica tem como consequência a formação de um líquido de cor escura, o chorume, que devido ao potencial poluidor pode contaminar o solo e as águas superficiais ou subterrâneas. Pode ocorrer também a formação de gases tóxicos, asfixiantes e explosivos que se acumulam no subsolo ou são lançados na atmosfera, o que deve ser repensado dando prioridade para a destinação final ambientalmente adequada.

Assim, buscar meios para um melhor gerenciamento dos resíduos urbanos, visando à redução da quantidade de materiais a serem dispostos em aterros, é uma questão importantíssima. Nesse sentido, a coleta seletiva é uma ferramenta de grande valia nesse aspecto, pela preservação ambiental e o desenvolvimento sustentável, podendo prolongar a vida útil de um aterro sanitário em aproximadamente um terço, ou seja, aproximadamente $32 \%$.

A coleta seletiva é uma das atividades de um plano de gerenciamento integrado de resíduos sólidos definido como o conjunto articulado de ações normativas, operacionais, financeiras e de planejamento que uma administração municipal desenvolve, baseado em critérios sanitários, ambientais e econômicos para coletar, tratar e dispor o lixo da cidade (PINHEL; ZANIN; MÔNACO, 2011). Nesse sentido, diversos são os trabalhos envolvendo a coleta seletiva: Conke e Nascimento (2018); Anjos et al. (2019); Sanjad et al. (2019). 
ANÁLISE TÉCNICA E ECONÔMICA

PARA IMPLANTAÇÃO DE UM

CENTRO DE COLETA SELETIVA EM

MONSENHOR PAULO - MG
Leonardo Martins da Silva Arantes

Thales Fernandes Leal

Rosângela Francisca de Paula Vitor Marques

Alisson Souza de Oliveira

A Lei 12.305 de agosto de 2010 incentiva a coleta seletiva de resíduos sólidos conforme sua composição ou constituição. A logística reversa é uma importante ferramenta na destinação ambientalmente adequada de resíduos perigosos como: resíduos de agrotóxicos, pilhas, baterias, lâmpadas fluorescentes e eletrônicos (BRASIL, 2010). Um dos importantes princípios é a responsabilidade compartilhada, que trouxe a obrigatoriedade para o manejo ambientalmente adequado dos resíduos sólidos entre governo, empresas e a sociedade civil. O poder público municipal deve realizar planos de gerenciamento dos resíduos sólidos urbanos e também impulsionar o retorno dos produtos após seu uso, processo no qual foi denominado de logística reversa. A lei consagra a participação formal dos catadores organizados em cooperativas na cadeia da reciclagem e estabelece, em seu Artigo 35, a obrigatoriedade de a população destinar de forma ambientalmente adequada seus resíduos recicláveis caso o município já possua o serviço de coleta seletiva (ALVARENGA, 2015).

Para Alvarenga (2015), a participação social infere no sucesso de programas de coleta seletiva, e há diferentes respostas sociais em relação à participação. Os programas podem ser agrupados em três tipos: grupo ativo, de participação eventual e os que não participam. A utilização dos PEV demanda maior esforço ao cidadão, que além de separar seu próprio "lixo", precisa se deslocar até o mesmo. Tal atitude quando rotineira demonstra um maior nível de conscientização, já que a internalização desse hábito é imprescindível para o sucesso dos programas de coleta seletiva. No entanto, as duas modalidades de coleta (Porta-a-Porta e por PEVs) apresentam aspectos positivos e negativos. Além da questão social, melhoria e qualidade de vida da população no município, juntamente com o potencial de retorno econômico presente nos resíduos recicláveis, tanto em relação ao centro de coleta do município, como para a população, dentro do benefício de troca do "material reciclável" por vale compra, como forma de compensar a participação e colaboração com o processo de funcionamento do Centro de Coleta Seletiva Municipal.

Berticelli et al. (2020) fez um levantamento a respeito da coleta seletiva no Brasil nas três dimensões da sustentabilidade: ambiental, social e econômica e concluiu que a coleta seletiva no Brasil ainda envolve pequenas iniciativas nos municípios, não abrangendo a totalidade da população. E que os indicadores utilizados são úteis para possibilitar o diagnóstico avaliando o grau de sustentabilidade e monitoramento dos programas de coleta seletiva, nos quais auxiliam nas definições de objetivos e metas para melhoria contínua.

Os parâmetros e diretrizes adotados no projeto foram definidos de acordo com a DELIBERAÇÃO NORMATIVA COMPAM № 214 (MINAS GERAIS, 2017), e seguem as linhas de ações dispostas na Deliberação Normativa supracitada, que define educação ambiental, o que significa que todos os aspectos no ambiente de aplicação do programa devem ser levados em consideração: 
ANÁLISE TÉCNICA E ECONÔMICA

PARA IMPLANTAÇÃO DE UM

CENTRO DE COLETA SELETIVA EM

MONSENHOR PAULO - MG
Leonardo Martins da Silva Arantes

Thales Fernandes Leal

Rosângela Francisca de Paula Vitor Marques

Alisson Souza de Oliveira

“Um processo de ensino-aprendizagem permanente e de abordagem sistêmica, o qual reconhece o conjunto das Inter relações entre âmbitos naturais, culturais, históricos, sociais, econômicos e políticos, com intuito de permitir que os grupos sociais envolvidos com o empreendimento adquiram conhecimentos, habilidades e atitudes para o empoderamento e pleno exercício da cidadania".

Neste contexto, objetivou-se neste trabalho avaliar técnica e economicamente a viabilidade de implantação de um sistema de coleta seletiva para o município de Monsenhor Paulo - MG, desde a quantidade dos resíduos gerados, até as estruturas e custos de implantação e operação de um Centro de Coleta Seletiva Municipal, e, consequentemente, reduzir custos com o gerenciamento dos resíduos sólidos urbanos e os impactos ambientais gerados pelos resíduos sólidos urbanos dentro do município.

\section{MATERIAL E MÉTODOS}

\section{Caracterização do município de Monsenhor Paulo}

Segundo IBGE (2020), Monsenhor Paulo é um município da unidade federativa Minas Gerais, da mesorregião Sul/Sudoeste de Minas Gerais, o qual possui população estimada, em 2020, de 8727 habitantes e a densidade demográfica de $37,69 \mathrm{hab} / \mathrm{Km}^{-2}$. Seu território é composto $100 \%$ pelo bioma Mata Atlântica. O IDHM de Monsenhor Paulo é 0.721. Segundo a Câmara Municipal de Monsenhor Paulo (2021), a economia do município é mista, onde a pequena e média indústria convivem com a agricultura e a pecuária. O município conta com um parque industrial do ramo moveleiro e do ramo siderúrgico. O município está ligado - 15km - à rodovia federal Fernão Dias na altura do Trevo para Campanha.

\section{Caracterização quantitativa dos resíduos gerados - Pesagem}

Realizou-se um levantamento do volume de resíduos domiciliares gerados no município de Monsenhor Paulo. Os caminhões do tipo compactadores com capacidade de $12 \mathrm{~m}^{3}$ utilizados para coleta do lixo no município foram pesados diariamente no período de 05 de fevereiro de 2018 a 02 de março de 2018 e 05 de abril a 02 de maio de 2018 em uma balança própria para caminhões, instalada na empresa MGM Produtos Siderúrgicos LTDA.

A pesagem foi realizada pesando-se o caminhão cheio, obtendo o peso bruto e após este descarregar o resíduo no aterro controlado do município, o caminhão foi pesado vazio, sendo este peso a tara. A diferença entre o peso bruto e o peso do caminhão vazio obtendo o peso líquido diário de resíduos gerados, possibilitando avaliação e estimativas de geração de resíduos no município. 
ANÁLISE TÉCNICA E ECONÔMICA

PARA IMPLANTAÇÃO DE UM

CENTRO DE COLETA SELETIVA EM

MONSENHOR PAULO - MG
Leonardo Martins da Silva Arantes

Thales Fernandes Leal

Rosângela Francisca de Paula Vitor Marques

Alisson Souza de Oliveira

\section{Visitas técnicas}

Afim de verificar os modelos utilizados para o sistema de gerenciamento de resíduos sólidos urbanos foi realizada visita técnica em dois modelos de centros de reciclagem: o primeiro de Três Corações - MG (modelo - 1) e o segundo de Nova Resende - MG (modelo - 2), caracterizado por ter aproximadamente 80.032 habitantes e Nova Resende com 16832 habitantes respectivamente, segundo a projeção do IBGE (2020), onde funcionam sistemas de coleta seletiva, com metodologias diferenciadas e que apresentaram bons resultados avaliados durante as visitas técnicas.

\section{Escolha do modelo de coleta seletiva}

Após as visitas técnicas realizadas nos municípios, os modelos 1 e 2 foram levantadas informações sobre diversos aspectos dos processos de coleta seletiva, como: troca de informações, dificuldades encontradas, erros e acertos, metodologias empregadas em cada um dos dois municípios. Bem como levou-se em conta características do porte do município, hábitos da população e aporte financeiro. Em razão dessas características optou-se pela escolha pelo modelo de coleta seletiva por barganha (troca).

\section{Pesquisa de mercado para compra e venda dos materiais recicláveis}

Para a quantificação do valor de venda de cada produto reciclável foi realizada pesquisa de mercado por material, com levantamentos de tomada de preço em três empresas diferentes que compram materiais recicláveis na região de Monsenhor Paulo - MG. Em relação ao preço de compra, utilizou-se a tabela de preços praticados pelo modelo de Nova Resende como referência, pois notouse que em todos os preços, havia um lucro significativo.

Proposição e quantificação de custos e aquisição de material para o Centro de Coleta

\section{Seletiva e o Mercado Municipal}

O levantamento de valores foi realizado por itens, através do contato com fornecedores de serviços, equipamentos e mobiliários, entre outros, para chegar a um valor aproximado para os investimentos, para a implantação do centro de triagem e do Mercado Municipal. Cabe ressaltar que não foi incluído o custo do galpão de funcionamento, o qual, posteriormente ficará sob a responsabilidade da Prefeitura Municipal de Monsenhor Paulo - MG.

\section{RESULTADOS E DISCUSSÕES}

\section{Pesagem dos resíduos sólidos urbanos do município:}

Após a pesagem de 2 meses (fevereiro e abril), com intervalo de um mês sem pesar, foi levantado a geração de resíduos de resíduos sólidos em Monsenhor Paulo - MG, o que deu em média 36 viagens de caminhão ao aterro controlado do município, levando pouco mais de noventa e três toneladas de resíduos por mês no local (tabela 1). 
ANÁLISE TÉCNICA E ECONÔMICA

PARA IMPLANTAÇÃO DE UM

CENTRO DE COLETA SELETIVA EM

MONSENHOR PAULO - MG
Leonardo Martins da Silva Arantes

Thales Fernandes Leal

Rosângela Francisca de Paula Vitor Marques

Alisson Souza de Oliveira

Observou-se que no mês de fevereiro maiores quantidades de resíduos foram observadas na terceira e quarta semana, muito possivelmente podendo estar associado ao carnaval, com maiores quantidades de resíduos gerados. Em abril as maiores gerações foram na primeira e quarta semana, fato que pode estar relacionado aos pagamentos e vales, o qual pode associar a um maior consumo. Sendo fatores considerados por Bidone e Povinelli (1999) que contribuem para a geração de resíduos sólidos urbanos

Ressalta-se a quantidade gerada de resíduos sólidos urbanos no município de Monsenhor Paulo abaixo da média nacional conforme ABRELPE (2017) de 1,04 Kg.pessoa.dia-1 com 9,1 ton/mês em média, ressaltando-se que a geração per capita gira em torno de 0,350 Kg.pessoa.dia-1 ${ }^{-1}$ se aproximando do modelo de coleta seletiva visitado de Nova Resende.

Tabela 1 - Quantificação dos resíduos gerados no município de Monsenhor Paulo nos meses de fevereiro e abril de 2018.

\begin{tabular}{ccccccc}
\hline & \multicolumn{2}{c}{ Fevereiro } & \multicolumn{2}{c}{ Abril } & \multicolumn{2}{c}{ Média mensal } \\
\cline { 2 - 7 } & $\begin{array}{c}\text { No } \\
\text { Pesagens }\end{array}$ & Peso em (Kg) & No Pesagens & $\begin{array}{c}\text { Peso em } \\
(\mathrm{Kg})\end{array}$ & $\begin{array}{c}\mathrm{N}^{\circ} \text { de } \\
\text { pesagens }\end{array}$ & $\begin{array}{c}\text { Peso } \\
(\mathrm{Kg})\end{array}$ \\
\hline 1ㅇ semana & 9 & 22280 & 10 & 25610 & 35,5 & 91370 \\
2o semana & 7 & 15850 & 9 & 22640 & & \\
3o semana & 9 & 27640 & 9 & 21530 & & \\
4o semana & 8 & 23860 & 10 & 23230 & & \\
\hline Total mensal & 33 & 89630 & 38 & 93110 & & \\
\hline
\end{tabular}

Fonte: Elaborado pelos autores (2018).

Com base nos dados do IPEA (2012) e fazendo-se a extrapolação para o município de Monsenhor Paulo, na Tabela 2 são apresentados a composição gravimétrica com quantidades de resíduos sólidos urbanos nas seguintes tipologias: Matéria orgânica, reciclável e rejeito.

Tabela 2 - Porcentual de tipologias de resíduos com base nos dados do IPEA.

\begin{tabular}{cccc}
\hline Peso Total (Ton) & Material & Porcentagem IPEA (\%) & Peso final (Ton) \\
\hline \multirow{2}{*}{91,3} & Orgânico & 51,0 & 46,5 \\
& Reciclável & 32,0 & 29,2 \\
& Rejeito & 17,0 & 15,5 \\
\hline
\end{tabular}

Fonte: Elaborado pelos autores (2018).

Assim, teoricamente $32 \%$ desse volume seria material reciclável, com estimativa de aproximadamente 30 toneladas que poderia retornar a cadeia produtiva gerando emprego e renda e vale compras para as pessoas que assim separassem esse material. Além de aumentar a vida útil do 
ANÁLISE TÉCNICA E ECONÔMICA

PARA IMPLANTAÇÃO DE UM

CENTRO DE COLETA SELETIVA EM

MONSENHOR PAULO - MG
Leonardo Martins da Silva Arantes

Thales Fernandes Leal

Rosângela Francisca de Paula Vitor Marques

Alisson Souza de Oliveira

local de disposição final dos resíduos sólidos urbanos, o que possivelmente acarretaria em menores quantidades de áreas a serem impactadas pelo resíduo.

\section{Caracterização do processo de coleta seletiva dos municípios utilizados no estudo}

No município de Três Corações-MG, é adotado um sistema de coleta porta a porta, ou seja, a população separa os materiais entre úmido (orgânicos e rejeitos) e seco (reciclável), em diversos bairros da cidade, utilizando um veículo específico para a operação. A coleta é realizada em dias alternados à coleta convencional de resíduos sólidos urbanos. Posteriormente o material é levado ao local de funcionamento da associação, onde é segregado, processado e enfardado, para que ocorra a destinação final.

Em Nova Resende-MG foi adotado outro modelo de coleta seletiva. O sistema funciona de modo que o material seja separado nas residências, sendo opção em separar: somente recicláveis ou resíduos secos ou separados por tipologias. O material separado nas residências é levado até o "Galpão da Associação de Catadores", (Figura 1A) onde ocorre a barganha (troca) desse material por um ticket (Vale Compras), como forma de incentivo pela participação. O vale compras, pode ser utilizado em uma rede de opções que compõe o sistema, sendo um Mercado Municipal (Figura1B e 1 C), no qual possui todos os tipos de produtos alimentícios e é abastecido com verduras e hortaliças, produzidos em uma horta integrante do sistema.

Figura 1A - Centro Municipal de coleta seletiva do município de Nova Resende - MG.

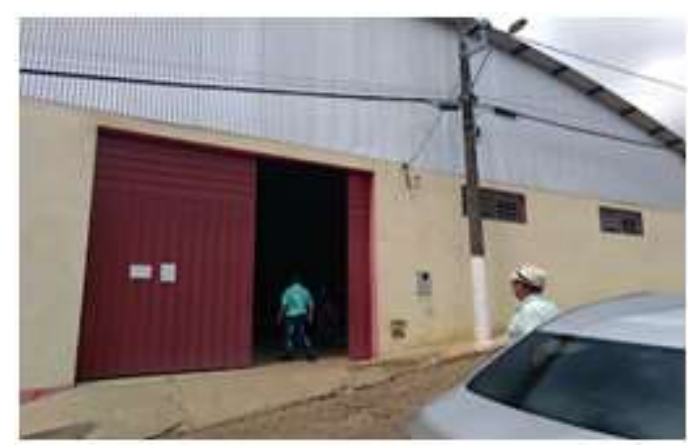

Fonte: Elaborado pelos autores (2018). 
Figura 1B - Mercado Municipal do município de Nova Resende - MG.

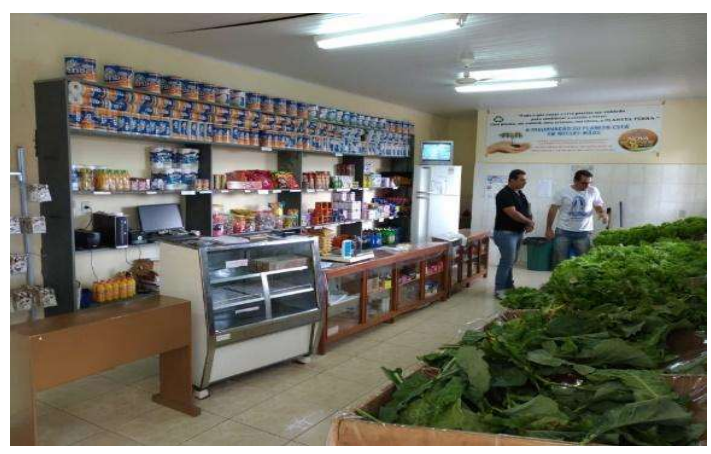

Fonte: Elaborado pelos autores (2018).

Figura 1C - Restaurante Municipal do município de Nova Resende - MG.

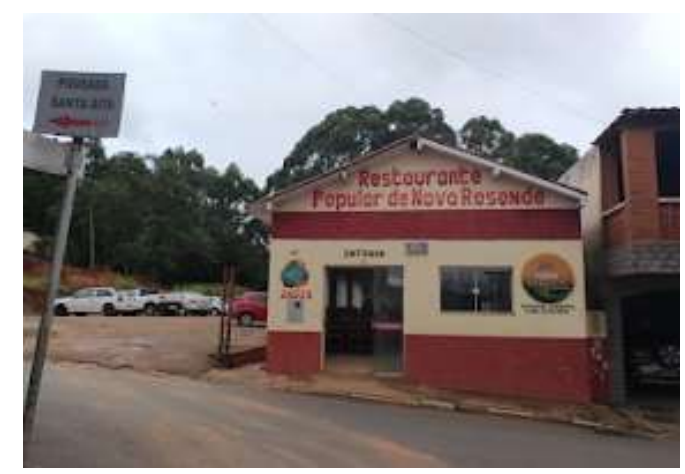

Fonte: Elaborado pelos autores (2018).

\section{Geração real de resíduos em Nova Resende - MG.}

Alguns fatores como culturais, hábitos de consumo, padrão de vida, número de habitantes e a renda familiar definem o poder de compra (BIDONE; POVINELLI, 1999). Assim, esses fatores devem ser levados em consideração para a escolha do melhor modelo para a implantação da coleta seletiva. Nesse sentido, optou-se em utilizar o modelo de Nova Resende devido à semelhança em termos do número de habitantes e hábitos de consumo, os quais influenciarão sobremaneira na quantidade de resíduos gerados. Assim, foi utilizado o percentual de geração de cada tipo de material reciclável, para estimar o percentual de cada um para Monsenhor Paulo. Na tabela 3, são apresentados os valores de geração consultados junto ao departamento de gerenciamento de Nova Resende-MG, valores reais.

Tabela 3 - Valores da geração de resíduos, percentual e preços de compra em Nova Resende-MG.

\begin{tabular}{ccccccc}
\hline Material & Quantidad & Percentua & Peso por & Preço & Gasto & Lucro \\
& e (Ton) & I (\%) & material & compra & estima & estimad \\
& & (Ton) & $(\mathrm{R} \$)$ & do (R\$) & o (R\$) \\
\hline
\end{tabular}




\begin{tabular}{ccccccc}
\hline Papelão & 8,35 & 39,7 & 11,59 & 0,12 & 1390,8 & 2318,00 \\
& & & & & 0 & \\
Plástico & 3,75 & 17,8 & 5,19 & 0,15 & 778,50 & 1816,50 \\
Metal & 6,10 & 29 & 8,46 & 0,15 & 1269 & 2961,00 \\
Vidro & 0,03 & 0,14 & 0,04 & 0,01 & 40,00 & 120,00 \\
Alumíni & 0,88 & 4,34 & 1,26 & 1,50 & 1890,0 & 3780,00 \\
o & & & & & 0 & \\
PEAD & 0,48 & 2,37 & 0,69 & 0,50 & 345,00 & 1104,00 \\
Cobre & 0,02 & 0,09 & 0,02 & 4,00 & 80,00 & 300,00 \\
Ráfia & 1,01 & 4,8 & 1,40 & 0,02 & 28,00 & 70,00 \\
Outros & 0,4 & 1,9 & 0,55 & - & 66,00 & - \\
\hline Total & 21,02 & 100 & 29,2 & & 5887,3 & 12469,5 \\
& & & & & & \\
\hline
\end{tabular}

Fonte: Elaborado pelos autores (2018).

Observou-se maior quantidade de papelão em relação a outros materiais $39,7 \%$, seguindo pela quantidade de metal e de plástico sendo de $29 \%$ e $17 \%$ respectivamente. A maior quantidade de papelão pode estar relacionada também aos comércios do município e grandes geradores, seguido por plásticos que se devem também por parcela da população e os hábitos de consumo.

Destaca-se na Tabela 3 que o preço adotado foi o preço intermediário, descartando o pior e o melhor preço oferecido pelas três empresas consultadas. Assim, o maior lucro estimado foi para o alumínio, seguido pelo metal e papelão respectivamente. Há de ressaltar que os lucros estimados variam em função do preço do tipo de material, assim o maior preço pago ainda é para o cobre, mas com quantidade de resíduos relativamente baixa.

\section{Estruturas e ferramentas necessárias}

Após as pesquisas de campo, referente a tudo que é necessário para operação do centro de coleta seletiva e do Mercado Municipal cotou-se os custos dos equipamentos necessários para o funcionamento do galpão, apresentado na tabela 4.

Tabela 4 - Custo de implantação dos equipamentos necessários ao funcionamento do galpão.

\begin{tabular}{cccc}
\hline Item & Ferramentas & Quantidade & Valor (R\$) \\
\hline 1 & Prensa enfardadeira & 1 & 25000,00 \\
2 & Paleteira & 1 & 2000,00 \\
3 & Girafa & 1 & 2500,00 \\
4 & Balança & 1 & 3000,00 \\
5 & Rolos de corda & 1 & 100,00 \\
6 & Mesa & 1 & 100,00 \\
7 & Calculadora & 2 & 20,00 \\
8 & Computador & 1 & 500,00 \\
9 & Facas & 5 & 50,00 \\
10 & Bags & 150 & 1000,00 \\
11 & Bebedouro & 1 & 250,00 \\
12 & Cadeira & 2 & 50,00
\end{tabular}




\begin{tabular}{cccc}
13 & Blocos de anotação & 5 & 300,00 \\
14 & Banner & 1 & 200,00 \\
15 & Balcão atendimento & 2 & 3000,00 \\
16 & Prateleiras & 8 & 4000,00 \\
\hline \multicolumn{4}{c}{ Total } \\
\hline
\end{tabular}

Fonte: Elaborado pelos autores (2018).

Para o funcionamento do sistema de Centro de Coleta Seletiva Municipal, é necessário um galpão que seja fechado e coberto, que atenda especificações ambientais e sanitárias. $O$ galpão deve ser destinado a receber os materiais pré-selecionados pela população do município, fazer a seleção secundária dos mesmos, e de acordo com cada material, processá-los e armazená-los para futura destinação final.

Os equipamentos e mobiliários dentro dele, para que possa operar, devem ser: balança, prensa enfardadeira, paleteira, girafa, rolos de cordas recicláveis, mesa, calculadora, computador, facas, bags, blocos de anotação, cadeiras, banner como tabela de preços, e para os funcionários do local, no mínimo, banheiro e bebedouro, caso os mesmos na hora da refeição, forem para casa, além é claro de acesso à água e à energia elétrica.

A proposição do Mercado Municipal, necessita de uma estrutura de um estabelecimento comercial, com água e energia elétrica e equipamentos e mobiliários como: balcão, balanças, prateleiras e bancadas. O qual deverá funcionar em recebimento e computação dos vales em troca de produtos alimentícios, atendimento, reposição de estoque e limpeza. E, ainda, o fornecimento de produtos alimentícios de qualidade em atendimento à população, pela colaboração no funcionamento do sistema de coleta seletiva do município.

Os produtos alimentícios a serem comercializados são os produtos que não são perecíveis, de fácil armazenamento, podendo ser mantido em temperatura ambiente, e, ainda os alimentos perecíveis que deverão ser refrigerados; utensílios domésticos básicos, produtos de limpeza e higiene pessoal.

Os preços tendem a serem praticados abaixo de outros pontos comerciais do município, considerando o principal objetivo do estabelecimento, que é o de incentivo e promoção à coleta seletiva e à ação social. Porém, esses preços seriam condicionados à troca por quantidades estipuladas de cada tipo de material reciclável. Assim, fazem-se necessários subsídios municipais, que podem ser através do ICMS Ecológico, porém cabe ressaltar que para a execução é imperativo a criação de legislações municipais.

O sistema pode funcionar todo por conta da prefeitura, ou seja, todos os funcionários necessários no processo serão de responsabilidade da prefeitura municipal de Monsenhor Paulo-MG, como pode ser também criado pela prefeitura uma cooperativa de catadores, ou ainda ONG's, porém, 
ANÁLISE TÉCNICA E ECONÔMICA

PARA IMPLANTAÇÃO DE UM

CENTRO DE COLETA SELETIVA EM

MONSENHOR PAULO - MG
Leonardo Martins da Silva Arantes

Thales Fernandes Leal

Rosângela Francisca de Paula Vitor Marques

Alisson Souza de Oliveira

nesses dois últimos casos é um processo um pouco mais lento e complicado, no qual o projeto passa a depender de duas frentes de trabalho. Portanto, optou-se somente por funcionários da prefeitura, sendo necessários dois operadores no Centro de Coleta Seletiva, um funcionário para o Mercado Municipal, sendo um, responsável também pelo gerenciamento de todo processo, fazendo a contabilização, tanto do Centro de Coleta como do mercado, avaliando e procedendo com a destinação dos materiais e compras de produtos para o mercado, sendo apresentado na Tabela 5, o custo fixo mensal para o funcionamento do galpão.

Tabela 5 - Custo fixo mensal para implantação do centro de triagem em Monsenhor Paulo.

\begin{tabular}{rrcc}
\hline & Item & Quantidade & Valor (R\$) \\
\hline 1 & Funcionários & 3 & $9.570,00$ \\
2 & Água & - & 30,00 \\
3 & Luz & - & 800,00 \\
4 & Bags & 50 & 250,00 \\
5 & Blocos anotação & 2 & 40,00 \\
\hline \multicolumn{2}{r}{ Total } & $10.690,00$ \\
\hline
\end{tabular}

Fonte: Elaborado pelos autores (2018).

Outro valor importante a ser levado em consideração, é em relação a economia com o caminhão de coleta de resíduos sólidos urbanos.

Estimou-se de maneira superficial, com base em informações do motorista do veículo coletor, o deslocamento de cerca de $25 \mathrm{~km}$ a cada viagem, sendo realizadas 35 viagens por mês com o veículo coletor. Se 32 \% de material reciclável for retirado de sua carga, pode-se reduzir no mínimo metade do percentual em relação às viagens.

A tabela 6 apresenta a redução de custos em relação a combustíveis. Cada viagem são $25 \mathrm{~km}$, considerando a média do veículo em $2 \mathrm{~km}$ por litro, sendo gastos 13 litros por viagem. O litro do óleo diesel em Monsenhor Paulo está em $\mathrm{R} \$ 3,78$ com estimativa de gasto por viagem de $\mathrm{R} \$ 49,04$ e, ainda desconsiderando o desgaste do veículo e tempo do motorista e os dois coletores.

Tabela 6 - Redução de custos em relação a combustíveis no período avaliado.

\begin{tabular}{cccc}
\hline Custo por viagem R\$ & $\begin{array}{c}\text { Custo mensal de } 35 \\
\text { viagens }\end{array}$ & Redução em percentual (\%) & Valor (R\$) \\
\hline 49,04 & 1719,90 & 16 & 317,52 \\
\hline
\end{tabular}

Fonte: Elaborado pelos autores (2018). 
ANÁLISE TÉCNICA E ECONÔMICA

PARA IMPLANTAÇÃO DE UM

CENTRO DE COLETA SELETIVA EM

MONSENHOR PAULO - MG
Leonardo Martins da Silva Arantes

Thales Fernandes Leal

Rosângela Francisca de Paula Vitor Marques Alisson Souza de Oliveira

\section{Fluxo de caixa}

O Fluxo de caixa estimado para o funcionamento do processo de coleta seletiva em Monsenhor Paulo, foi feito de forma geral, pois ainda existem fatores que podem influenciar, são muitas variáveis e condicionantes que podem interferir diretamente nesse levantamento, porém, acredita-se ser uma base muito útil na hora de avaliar em relação à implantação do projeto (Tabela 7).

Tabela 7 - Fluxo de caixa.

\begin{tabular}{|c|c|c|c|}
\hline \multicolumn{2}{|c|}{ Investimento } & \multicolumn{2}{|c|}{$\mathrm{R} \$ 42070,00$} \\
\hline \multicolumn{2}{|c|}{ Custo Mensal(R\$) } & \multicolumn{2}{|c|}{ Lucro mensal(R\$) } \\
\hline Operação & Compra & Venda & Economia \\
\hline 5905,60 & 5887,30 & 12469,50 & 317,52 \\
\hline \multicolumn{2}{|c|}{ Total } & \multicolumn{2}{|c|}{ Total } \\
\hline \multicolumn{2}{|c|}{11792,90} & \multicolumn{2}{|c|}{12786,50} \\
\hline \multicolumn{2}{|c|}{ Lucro -liquido } & \multicolumn{2}{|c|}{993,60} \\
\hline
\end{tabular}

Fonte: Elaborado pelos autores (2018).

Ressalta-se que o lucro líquido é de apenas $R \$ 993,60$. Entretanto, conforme mencionado, a partir das estipulações de quantidade de cada material reciclado. Assim, apesar de preços abaixo do valor de mercado, o lucro do Mercado Municipal é ainda estimado em média de aproximadamente $20 \%$ sobre o preço pago nos produtos adquiridos para o mercado, a partir de subsídios municipais. Assim, a porcentagem abaixo da média de outros comércios se dá pela proposta de atrativo ao programa de coleta seletiva no município de Monsenhor Paulo - MG, além de reduzir custos ambientais e com a saúde pública, quando a operação é ambientalmente adequada. Em estudo realizado por Rodrigues e Santana (2012), avaliando a viabilidade econômica da implantação da coleta seletiva em comparação com a coleta convencional em Palmas-TO concluiu também que a variação econômica do bem-estar do cidadão não pode ser compensada com a implantação da coleta seletiva. Porém, os mesmos autores destacaram a importância da implantação da coleta seletiva, uma vez que os inúmeros benefícios que a coleta seletiva traz para as gerações atuais e futuras extrapolam a avaliação econômica dos indivíduos sobre seu bem-estar presente.

Cabe ressaltar também que deve ser realizado campanhas educacionais e informativos para que o projeto possa ser validado, haja vista que a participação da sociedade é imprescindível para o sucesso da coleta seletiva. Segundo Bringhenti e Günther (2011), a efetividade de programas e iniciativas de coleta seletiva é imperativa sobre o envolvimento dos cidadãos, considerados, no extremo da cadeia de produção e consumo, os geradores dos resíduos sólidos. E, para que o programa de coleta seletiva seja de sucesso, deve-se haver informações e divulgações dos programas/iniciativas implantados, sendo que a comunidade deve estar sensibilizada e motivada com incorporação no 
cotidiano. Assim, acredita-se que com o projeto e incentivo a troca por alimentos com menor preço associado às divulgações possa vir a ser um "case" de sucesso, com vistas a assegurar sua operacionalização, viabilidade e continuidade para garantir a sustentabilidade do programa.

\section{Caracterização do galpão}

O galpão a ser instalado possui área de 219 metros quadrados. O mesmo será implantado na rua Santos Baldim, número 12, centro de Monsenhor Paulo, conforme planta baixa apresentada na Figura 2.

Figura 2 - Fluxograma de funcionamento para o município de Monsenhor Paulo.

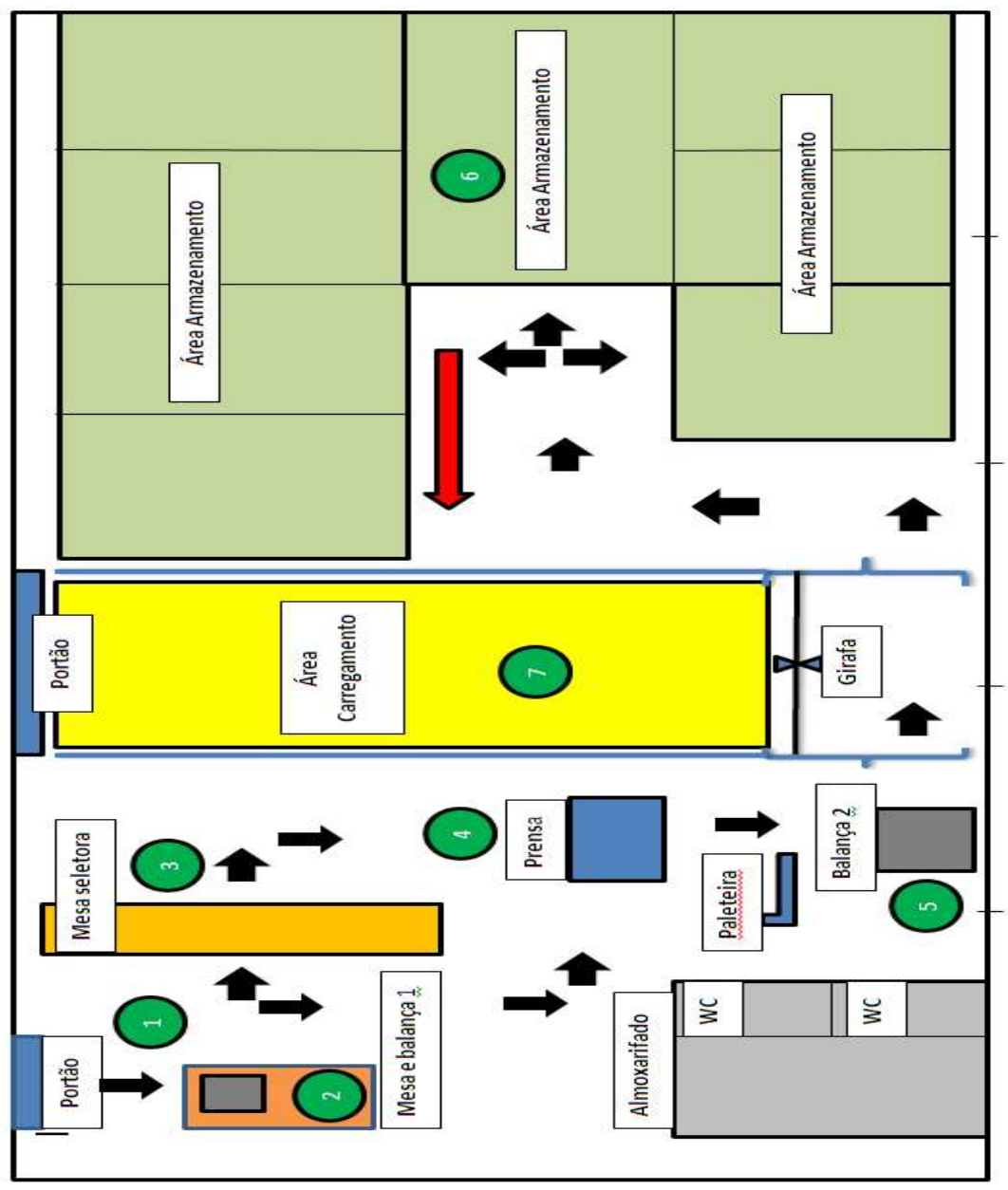

Fonte: Elaborado pelos autores (2018).

O local foi escolhido por já ser uma área disponível no município para a implantação de estruturas que tragam benefício à população paulense, além de ser um ponto favorável, por estar localizado no centro, área próxima toda plana, de fácil acesso aos moradores, próxima a outras 
ANÁLISE TÉCNICA E ECONÔMICA

PARA IMPLANTAÇÃO DE UM

CENTRO DE COLETA SELETIVA EM

MONSENHOR PAULO - MG
Leonardo Martins da Silva Arantes

Thales Fernandes Leal

Rosângela Francisca de Paula Vitor Marques

Alisson Souza de Oliveira

benfeitorias municipais em local adequado de acordo com a lei de parcelamento do solo e o zoneamento.

O layout foi feito através do levantamento de espaço disponível do terreno a ser utilizado, assim como do estudo de necessidades de materiais e ferramentas necessárias para o funcionamento do galpão. Depois foram realizadas as medidas de cada item necessário no seu lugar, de acordo com a logística de funcionamento a ser implantada, pensando em cada etapa de funcionamento dentro do Centro de Coleta Seletiva, pensando no fluxo dos materiais desde o recebimento, pesagem, separação, prensagem, enfardamento, armazenamento e destino final.

As figuras 3 e 4 apresentam a área em que o galpão deverá ser instalado.

Figura 3 - Área do centro de Coleta Seletiva Municipal.

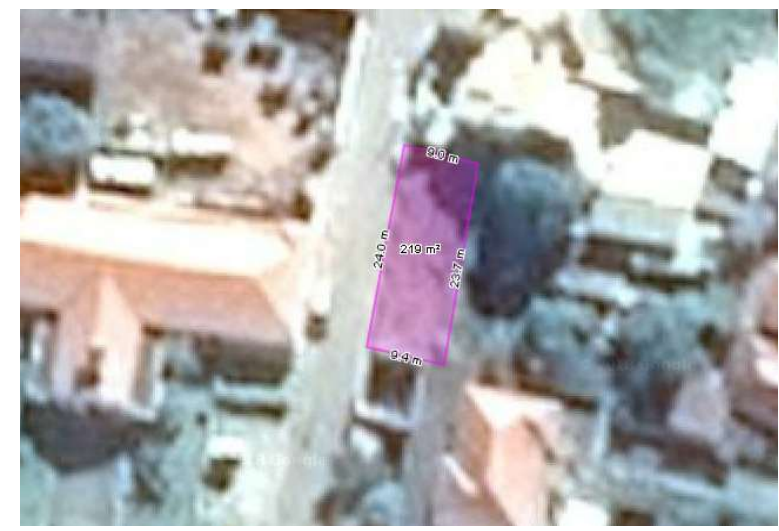

Fonte: Prefeitura de Monsenhor Paulo (2018).

Figura 4 - Ponto de instalação do centro da Coleta Seletiva Municipal.

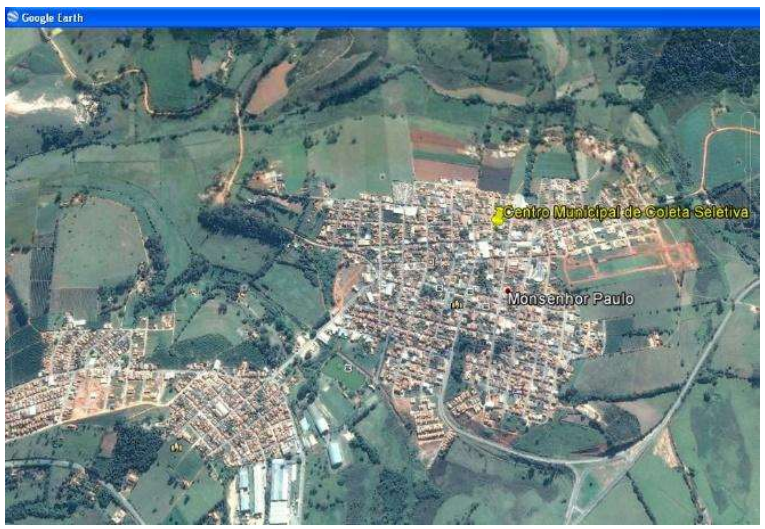

Fonte: Prefeitura de Monsenhor Paulo (2018).

O fluxograma de funcionamento do Centro de Coleta Seletiva (Figura 5) proposto será da seguinte maneira, o material é separado pelo cidadão em sua residência, depois levado ao Centro de Coleta Seletiva. Assim, o material é recebido, pesado, segregado, prensado, armazenado, depois é 
ANÁLISE TÉCNICA E ECONÔMICA

PARA IMPLANTAÇÃO DE UM

CENTRO DE COLETA SELETIVA EM

MONSENHOR PAULO - MG
Leonardo Martins da Silva Arantes

Thales Fernandes Leal

Rosângela Francisca de Paula Vitor Marques

Alisson Souza de Oliveira

carregado no veículo, pesado novamente e parte para o destino final. O cidadão que recebeu o ticket alimento, vai ao mercado, troca o ticket que recebeu, pelo alimento ou utensílio desejado.

Figura 5 - Fluxograma do centro de triagem.

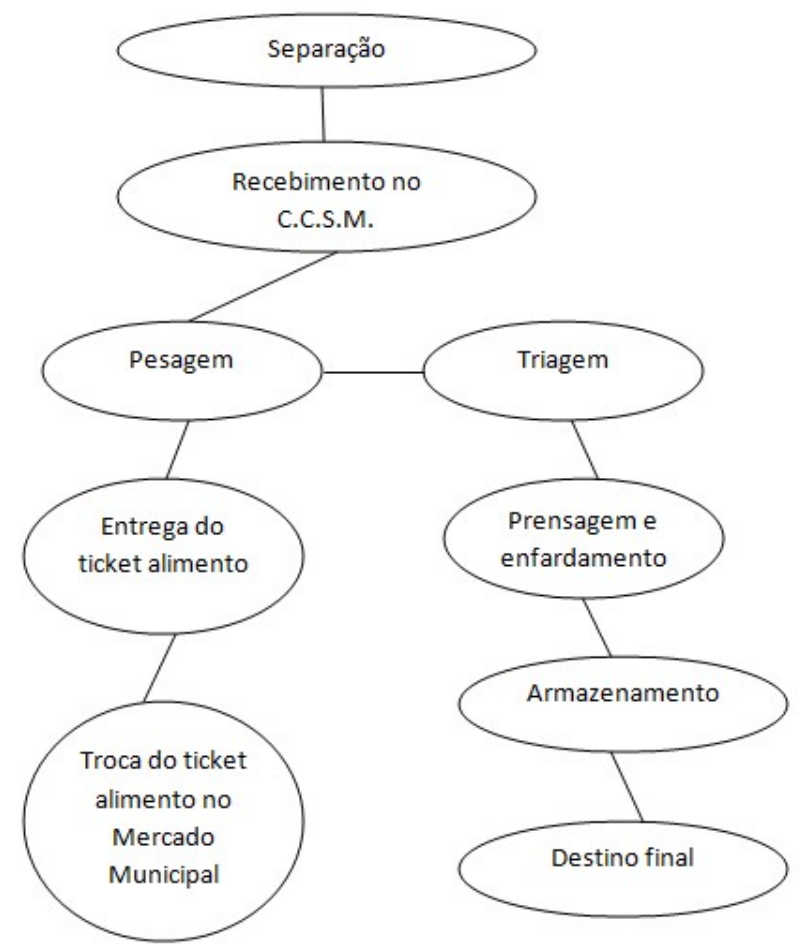

\section{C.C.S. M - Centro de Coleta Seletiva Municipal}

Fonte: Elaborado pelos autores (2018).

\section{CONSIDERAÇÕES FINAIS}

Quando se fala em projetos que possam trazer benefícios ambientais e sociais, deve-se considerar os fatores positivos, como a redução de descarte e aproveitamento de resíduos que seriam descartados como rejeitos, transformando-os em materiais recicláveis, geração de emprego e renda, ou seja, é um projeto que visa à sustentabilidade ambiental.

Porém, como na maioria dos projetos ambientais, existe um custo para implantação e manutenção do mesmo. Na estimativa do fluxo de caixa, o custo operacional está abaixo do lucro, ou seja, teoricamente o projeto se manteria, porém foi projetado um valor em cima de $100 \%$ da coleta de materiais recicláveis dentro do município, o que seria algo muito distante de acontecer em curto prazo, levando em consideração a cultura tanto local como do País, sendo portanto, a falta de hábito de separar o seu resíduo domiciliar, o que possivelmente perpassa por hábitos culturais ou a falta de percepção quanto à educação ambiental. 
ANÁLISE TÉCNICA E ECONÔMICA

PARA IMPLANTAÇÃO DE UM

CENTRO DE COLETA SELETIVA EM

MONSENHOR PAULO - MG
Leonardo Martins da Silva Arantes

Thales Fernandes Leal

Rosângela Francisca de Paula Vitor Marques

Alisson Souza de Oliveira

Diante dos valores apresentados, e de todas as variáveis que existem nesta linha de trabalho, observou-se que um projeto deste porte, poderá somente acontecer com o apoio e vontade das políticas públicas, investimentos ou por meio de organizações não governamentais - ONG 's sem visar lucros financeiros. O grande benefício está na questão ambiental, social e de saúde pública.

Algo a ser avaliado, futuramente, em relação à implantação do projeto no município, onde se acredita que daria um peso maior ao mesmo, seria a estimativa de gasto a destinar ou construir um aterro sanitário, visto que na atualidade faz-se o descarte/disposição final em aterro controlado, o que já não é mais permitido por Lei 12305/2010 (BRASIL, 2010).

Sendo assim, conclui-se que ambientalmente o projeto é extremamente viável, pois deixaria de ser descartado no solo do aterro controlado cerca de 32 toneladas mês de resíduos sólidos urbanos, com a ressalva de que a manutenção do aterro, necessitaria de verbas advindas do poder público para o seu pleno funcionamento, pois somente a arrecadação do Centro de Coleta Seletiva e do Mercado Municipal não seriam suficientes.

Em relação à questão social, o benefício à população é avaliado de forma positiva, principalmente às famílias de menor renda, que encontrariam uma alternativa na busca por alimentos e utensílios, e ainda, pode-se sanar problemas de saúde pública, quando esses resíduos são dispostos de maneira ambientalmente adequada.

\section{REFERÊNCIAS}

ABRELPE. Panorama dos resíduos sólidos no Brasil 2015. São Paulo: ABRELPE, 2016.

ABRELPE. Panorama dos resíduos sólidos no Brasil 2017. São Paulo: ABRELPE, 2017.

ANJOS, J. S. et al. Mobilização e implantação da coleta seletiva no município de Guanhães. Revista Gestão \& Sustentabilidade Ambiental, [S. I.], v. 8, n. 1, p. 600-628, 2019.

ALVARENGA, J. C. F. Gerenciamento de resíduos sólidos urbanos: uma análise da distribuição espacial dos pontos de entrega voluntária de material reciclável em Viçosa/MG. Revista Políticas Públicas \& Cidades, [S. I.], v. 2, n. 1, p. 45-66, 2015.

BERTICELLI, R. et al. Contribuição da coleta seletiva para o desenvolvimento sustentável municipal. Revista em Agronegócios e Meio Ambiente, Maringá, PR, v. 13 , n. 2, p. 781-796, 2020.

BIDONE, F. R. A.; POVINELLI, J. Conceito básico de resíduos sólidos. São Carlos: EESC: USP, 1999.

BRINGHENTI, Jacqueline R .; GÜNTHER, Wanda M. Risso. Participação social em programas de coleta seletiva de resíduos sólidos urbanos. Engenharia Sanitaria e Ambiental, Rio de Janeiro, v. 16, n. 4, p. 421-430, 2011. Disponível em http://www.scielo.br/scielo.php?script=sci_arttext\&pid=S1413$41522011000400014 \&$ Ing=en\&nrm=iso. Acesso em: 26 jan. 2021. 
BRASIL. Lei no 12.305, de 2 de agosto de 2010. Institui a Política Nacional de Resíduos Sólidos; altera a Lei no 9.605, de 12 de fevereiro de 1998; e dá outras providências. Brasília, DF: Presidência da República, 2010.

CÂMARA MUNICIPAL DE MONSENHOR PAULO. História de Monsenhor Paulo. MONSENHOR PAULO CÂMARA MUNICIPAL, $\quad[S . \quad$ l.], $2021 . \quad$ Disponível em: http://camaramonsenhorpaulo.mg.gov.br/historia/. Acesso em: 26 jan. 2021.

MINAS GERAIS (Estado). Conselho Estadual de Política Ambiental. Deliberação Normativa COPAM no 214, de 26 de abril de 2017. Estabelece as diretrizes para a elaboração e a execução dos Programas de Educação Ambiental no âmbito dos processos de licenciamento ambiental no Estado de Minas Gerais. Diário do Executivo de Minas Gerais, Belo Horizonte, p. 10, 29 abr. 2017.

CONKE, L. S.; NASCIMENTO, E. P. A coleta seletiva nas pesquisas brasileiras: uma avaliação metodológica. Revista Brasileira de Gestão Urbana, [S. I.], v. 10, n. 1, p. 199-212, 2018.

GOUVEIA, N.; PRADO, R. R. Riscos à saúde em áreas próximas a aterros de resíduos sólidos urbanos. Revista Saúde Pública, [S. I.], v. 44, n. 5, p. 859-866, 2010.

IBGE. Brasil / Minas Gerais / Nova Resende. IBGE, [S. I.], 2020. Disponível em: https://cidades.ibge.gov.br/brasil/mg/nova-resende/panorama. Acesso em: 26 jan. 2021.

IPEA. Diagnóstico dos resíduos sólidos urbanos: relatório de pesquisa. Brasília, DF: IPEA, 2012. Disponível em: https://www.ipea.gov.br/portal/images/stories/PDFs/relatoriopesquisa/121009_relatorio_residuos_ solidos_urbanos.pdf. Acesso em: 26 jan. 2021.

LANZA, V. C. V. Caderno técnico de reabilitação de áreas degradadas por resíduos sólidos urbanos. Belo Horizonte: Fundação Estadual de Meio Ambiente, 2009.

PINHEL, J. R.; ZANIN, M.; MÔNACO, G. Catador de resíduos recicláveis: um perfil profissional em construção. In: ZANIN, M.; GUTIERREZ, R. F. Cooperativas de catadores: reflexões sobre práticas. São Carlos: Claraluz, 2011. p. 169-210.

PREFEITURA DE MONSENHOR PAULO. Prefeitura de Monsenhor Paulo. [Monsenhor Paulo]: Google Earth, 2018. 1 imagem de satélite, color, 3D. Lat. 21ㄴ5'23"S, 4532'18"W. Disponível em: https://earth.google.com/web/search/centro+de+coleta+seletiva,+Monsenhor+Paulo,+MG/@$21.75613432,-$ 45.53942403,898.78886509a,135.57885082d,35y,13.10406202h,2.53321917t,359.99999914r/data= CigiJgokCWSCFOxdvDXAETfUUubrwTXAGUu9DrswwkbAISBRDR9|xkbA. Acesso em: 18 nov. 2018.

RODRIGUES, Waldecy; SANTANA, Willian Cardoso. Análise econômica de sistemas de gestão de resíduos sólidos urbanos: o caso da coleta de lixo seletiva em Palmas, TO. Revista Brasileira de Gestão Urbana, Curitiba, v. 4, n. 2, p. 299-312, 2012. Disponível em: http://www.scielo.br/scielo.php?script=sci_arttext\&pid=S2175$33692012000200011 \& \operatorname{lng}=e n \& n r m=i s o$. Acesso em: 26 jan. 2021.

SANJAD, H. C.; ARAÚJO JUNIOR, A. J. S.; COSTA, C. E. A. S. Reciclagem como alternativa para reduzir despesas gerenciais no setor de resíduos. Revista Observatorio de la Economía Latinoamericana, [S. l.], p. 1-15, 2019. Disponível em: https://www.eumed.net/rev/oel/2019/12/reciclagem-reduzirresiduos.html. Acesso em: 26 jan. 2021. 